\title{
Chitosan nanoparticles release nimodipine in response to tissue acidosis to attenuate spreading depolarization evoked during forebrain ischemia
}

\author{
Orsolya M. Tóth ${ }^{\mathrm{a}}$, Ákos Menyhárt ${ }^{\mathrm{a}}$, Viktória Éva Varga ${ }^{\mathrm{a}}$, Dóra Hantosi ${ }^{\mathrm{a}}$, Orsolya Ivánkovits-Kiss ${ }^{\mathrm{a}}$, \\ Dániel Péter Varga ${ }^{\mathrm{a}}$, Írisz Szabóa ${ }^{\mathrm{a}}$, László Janovák ${ }^{\mathrm{b}}$, Imre Dékány ${ }^{\mathrm{b}}$, Eszter Farkas ${ }^{\mathrm{a}, *}$, Ferenc Bari $^{\mathrm{a}}$ \\ ${ }^{a}$ Department of Medical Physics and Informatics, Faculty of Medicine \& Faculty of Science and Informatics, University of Szeged, H-6720, Szeged, Korányi fasor 9, \\ Hungary \\ ${ }^{\mathrm{b}}$ University of Szeged, Interdisciplinary Excellence Centre, Department of Physical Chemistry and Materials Science, H-6720, Rerrich Béla tér 1, Szeged, Hungary
}

\section{H I G H L I G H T S}

- Tissue acidosis with cerebral ischemia was exploited for controlled drug release.

- Nimodipine release from nanoparticles to low $\mathrm{pH}$ was shown in ischemic brain tissue.

- Nimodipine delivered by nanoparticles improved perfusion in ischemic brain tissue.

- Nimodipine delivered by nanoparticles inhibited spreading depolarization.

- The applied chitosan nanoparticles did not activate microglia in the brain.

\section{A R T I C L E I N F O}

\section{Keywords:}

Acidosis

Cerebral blood flow

Cerebral ischemia

Nanomedicine

Nimodipine

Spreading depolarization

\begin{abstract}
A B S T R A C T
Stroke is an important cause of mortality and disability. Treatment options are limited, therefore the progress in this regard is urgently needed. Nimodipine, an L-type voltage-gated calcium channel antagonist dilates cerebral arterioles, but its systemic administration may cause potential side effects. We have previously constructed chitosan nanoparticles as drug carriers, which release nimodipine in response to decreasing $\mathrm{pH}$ typical of cerebral ischemia. Here we have set out to evaluate this nanomedical approach to deliver nimodipine selectively to acidic ischemic brain tissue.

After washing a nanoparticle suspension with or without nimodipine $(100 \mu \mathrm{M})$ on the exposed brain surface of anesthetized rats $(n=18)$, both common carotid arteries were occluded to create forebrain ischemia. Spreading depolarizations (SDs) were elicited by $1 \mathrm{M} \mathrm{KCl}$ to deepen the ischemic insult. Local field potential, cerebral blood flow (CBF) and tissue $\mathrm{pH}$ were recorded from the cerebral cortex. Microglia activation and neuronal survival were evaluated in brain sections by immunocytochemistry.

Ischemia-induced tissue acidosis initiated nimodipine release from nanoparticles, confirmed by the significant elevation of baseline CBF ( $47.8 \pm 23.7$ vs. $29.3 \pm 6.96 \%)$. Nimodipine shortened the duration of both SD itself $(48.07 \pm 23.29$ vs. $76.25 \pm 17.2 \mathrm{~s})$, and the associated tissue acidosis (65.46 \pm 20.2 vs. $138.3 \pm 66.07 \mathrm{~s})$, moreover it enhanced the SD-related hyperemia (48.15 \pm 42.04 vs. $17.29 \pm 11.03 \%)$. Chitosan nanoparticles did not activate microglia.

The data support the concept that tissue acidosis linked to cerebral ischemia can be employed as a trigger for targeted drug delivery. Nimodipine-mediated vasodilation and SD inhibition can be achieved by pH-responsive chitosan nanoparticles applied directly to the brain surface.
\end{abstract}

\section{Introduction}

Even though ischemic stroke is increasingly more prevalent in the aging Western societies, treatment options with reasonable success rate are limited to systemic thrombolysis or endovascular thrombectomy, both feasible to conduct in a selected group of all stroke patients (Balami et al., 2013; Campbell et al., 2015). The development of other effective treatment options that may be beneficial to a large population

\footnotetext{
* Corresponding author. Department of Medical Physics and Informatics, Faculty of Medicine, and Faculty of Science and Informatics, University of Szeged, Korányi fasor 9, H-6720, Szeged, Hungary.

E-mail address: farkas.eszter.1@med.u-szeged.hu (E. Farkas).
} 


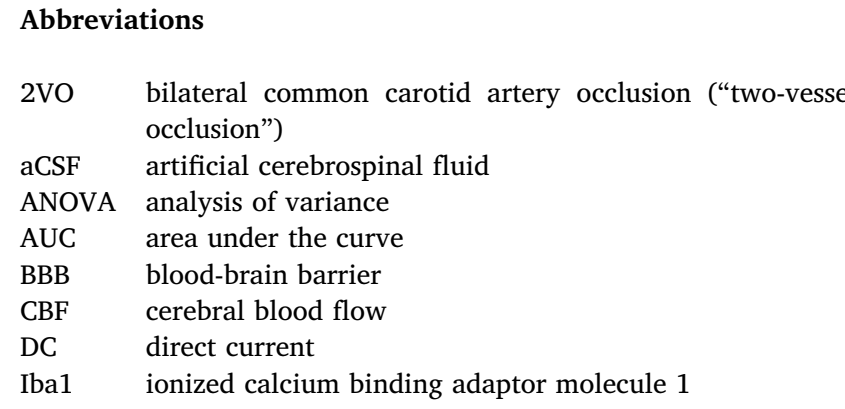

of stroke patients is urgently needed.

The focus of stroke therapy is the salvage of non-functional but viable penumbra tissue surrounding the ischemic core beyond rescue. Spreading depolarization (SD) has been recognized as a central mechanism of injury progression and of the conversion of penumbra tissue to the ischemic core (Nedergaard et al., 1996; Hossmann, 1996; Woitzik et al., 2013; Hartings et al., 2017; Hertelendy et al., 2019). Delayed cerebral ischemia after aneurismal subarachnoid hemorrhage (SAH) has been also linked to SD (Dreier et al., 2006), and SD-induced ischemia (Dreier et al., 2009). Importantly, SD-induced ischemia was found to occur in the time window of the development of brain infarcts confirmed by serial neuroimaging (Lückl et al., 2018).

Spreading depolarization has recently been considered as a presumed target of pharmacological neuroprotective intervention (Hertle et al., 2012; Carlson et al., 2018). Next to the NMDA receptor blocker ketamine (Sánchez-Porras et al., 2014; Reinhart and Shuttleworth, 2018), the L-type voltage-gated calcium channel antagonist nimodipine has been found effective to impede SD (Richter et al., 2002; Menyhárt et al., 2018; Szabó et al., 2019), or to counteract the ischemia-related impairment of the cerebral blood flow (CBF) response to SD (Dreier et al., 1998, 2002; Menyhárt et al., 2018; Szabó et al., 2019).

In clinical setting, nimodipine administered orally or intravenously has become an approved agent to prevent delayed cerebral ischemia after aneurismal subarachnoid hemorrhage (SAH) (Pickard et al., 1989; van Gijn et al., 2007). Prophylactic treatment with nimodipine was found to reduce the frequency and severity of delayed ischemic stroke (Pickard et al., 1989; Dorhout Mees et al., 2007). In addition, some clinical trials have suggested that nimodipine may limit infarct growth in acute ischemic stroke, as well (Martinez-Vila et al., 1990; Fogelholm et al., 2000). Yet, the systemic administration of nimodipine is limited by its suboptimal efficacy and the dose-dependent hypotension it may produce in some patients (Sandow et al., 2016). Also, the pharmacological augmentation of the CBF response to SD at optimally perfused brain sites distant to the ischemic penumbra may cause steal effect, and ultimately increase the risk of ischemic injury expansion (Pinard et al., 2002). All these drawbacks together justify the development of drug delivery systems targeting selectively the tissue at risk of injury, to achieve neuroprotection without counterproductive side effects.

The use of biocompatible and biodegradable micro- or nanoparticles that may be selectively targeted to desired tissue sites has been recently gaining increasing significance. Nimodipine, for instance, has been associated to poly-D,L-lactide-co-glycolide (PLGA) microparticles and applied intrathecally in order to achieve local, prolonged release of the drug in experimental SAH (Hänggi et al., 2012), an approach later taken to a clinical study, to be tested in patients surgically treated for aneurismal SAH (Etminan et al., 2015). Here we set out to explore whether nimodipine can be targeted with nanoparticles selectively to brain tissue affected by ischemia, to inhibit recurrent SD events perceived to be harmful to the survival of the penumbra. We have recently constructed hydrophobized and $\mathrm{pH}$ - sensitive chitosan nanoparticles, which release nimodipine in response to an acidic $\mathrm{pH}$ shift (from $\mathrm{pH} 7.3$ to $\sim 6.9$ ), the drug release having been confirmed in suspension
LDF laser-Doppler flow

LFP local field potential

MABP mean arterial blood pressure

NeuN neuronal nuclear protein

NMDA N-methyl-D-aspartate

PFA paraformaldehyde

rSD recurrent spreading depolarization

SAH subarachnoid hemorrhage

SD spreading depolarization

SD1 the first spreading depolarization in a train of events
(Janovák et al., 2018). Decreasing pH has been utilized as the trigger of drug release from nanoparticles, because ischemia produces local tissue acidosis, which is further worsened by the occurrence of SDs (Menyhárt et al., 2017). Nanoparticles responsive to $\mathrm{pH}$ gradients were previously designed for cancer therapy (Shen et al., 2008; Du et al., 2014), because the increased metabolism of glucose creates extracellular acidosis in solid tumors (Neri and Supuran, 2011), which can be exploited for targeted drug delivery.

In the present study, we applied nimodipine associated to $\mathrm{pH}$ responsive chitosan nanoparticles $(\mathrm{d}=5.2 \pm 1.1 \mathrm{~nm}$ ) (Janovák et al., 2018) to the exposed cerebral cortex of rats to investigate (i) whether tissue acidosis caused by ischemia or SD occurrence initiates drug release in the nervous tissue, and (ii) whether nimodipine administered with nanoparticles exerts its expected vasodilator and neuroprotective effect against SD propagating over the penumbra. With encouraging data in hand, we aim to build upon these results and design, in future work, an approach for the systemic administration of the $\mathrm{pH}$ responsive chitosan nanoparticles.

\section{Materials and methods}

\subsection{Surgical procedures}

All experiments were approved by the National Food Chain Safety and Animal Health Directorate of Csongrád County, Hungary. The procedures conformed to the guidelines of the Scientific Committee of Animal Experimentation of the Hungarian Academy of Sciences (updated Law and Regulations on Animal Protection: 40/2013. (II. 14.) Gov. of Hungary), following the EU Directive 2010/63/EU on the protection of animals used for scientific purposes and reported in compliance with the ARRIVE guidelines.

Young adult, male Sprague-Dawley rats (Charles River Laboratories; $\mathrm{n}=25, \mathrm{~m}=339 \pm 37 \mathrm{~g}$ ) were used in this study. Animals were housed under a normal $12 / 12 \mathrm{~h}$ light/dark cycle and constant temperature $\left(23^{\circ} \mathrm{C}\right)$. Standard rodent chow and drinking water were supplied ad libitum. On the day of experiments, animals were anesthetized with isoflurane (1.5-2\% in $\mathrm{N}_{2} \mathrm{O}: \mathrm{O}_{2} 70 \%: 30 \%$ ) and allowed to breathe spontaneously through a head mask. Body temperature was maintained at $37 \pm 0.5^{\circ} \mathrm{C}$ by using a servo-regulated heating pad, feedback-controlled by a flexible rectal probe (Harvard Apparatus, Holliston, MA, U.S.A.). Atropine $(0.1 \%, 0.05 \mathrm{ml})$ was administered intramuscularly shortly before the surgical procedures to avoid the production of airway mucus. Lidocaine (1\%) was administered topically before opening each tissue layer. The left femoral artery was cannulated to monitor mean arterial blood pressure (MABP) continuously, and to collect samples for arterial blood gas analysis. Samples for blood gas analysis were taken prior to the start of the experimental protocol (physiological condition) and shortly after the evolution of the last SD event in a train (ischemic condition) (Epoc Reader, Epocal, Ottawa, Canada). The depth of anesthesia was regularly checked and controlled with the aid of MABP. Both common carotid arteries were carefully separated from the surrounding tissue and an occluder was looped around each vessel for later 
induction of acute, incomplete, global forebrain ischemia. The head of the rats was fixed into a stereotactic frame and two cranial windows $(\sim 3 \times 3 \mathrm{~mm})$ were prepared on the right parietal bone ( $3 \mathrm{~mm}$ caudal, $5 \mathrm{~mm}$ lateral and $7 \mathrm{~mm}$ caudal, $5 \mathrm{~mm}$ lateral from bregma) with a high precision dental drill (ProLab Basic, Bien-Air Dental SA, Bienne, Switzerland) under saline cooling $(n=18)$. The cortical surface was exposed by the careful retraction of the dura mater in each cranial window. The caudal window was later used for evoking SDs, whereas a $\mathrm{pH}$ sensitive microelectrode, a reference electrode recording local field potential filtered in direct current (DC) mode, and an adjacent LaserDoppler probe were positioned in the rostral window. The craniotomies were regularly irrigated with artificial cerebrospinal fluid (aCSF; mM concentrations: $126.6 \mathrm{NaCl}, 3 \mathrm{KCl}, 1.5 \mathrm{CaCl}_{2}, 1.2 \mathrm{MgCl}_{2}, 24.5 \mathrm{NaHCO}_{3}$, 6.7 urea, 3.7 glucose bubbled with $95 \% \mathrm{O}_{2}$ and $5 \% \mathrm{CO}_{2}$ to achieve a constant $\mathrm{pH}$ of 7.4). In order to discriminate the degree of microglia activation caused by SDs themselves with respect to the impact of trepanation alone, the cranial windows were created bilaterally in some rats $(\mathrm{n}=7)$.

\subsection{Recording of extracellular $p H$, electrophysiological variables and local cerebral blood flow}

Ion-sensitive microelectrodes were prepared according to Voipio and Kaila (1993). Glass capillary microelectrode tips (outer diameter: $10-12 \mu \mathrm{m}$ ) were filled with a liquid $\mathrm{H}^{+}$ion exchanger, and the shank of the microelectrode was backfilled with $150 \mathrm{mM} \mathrm{NaCl}+40 \mathrm{mM}$ HEPES $+20 \mathrm{mM} \mathrm{NaOH}$. Each $\mathrm{pH}$ sensitive microelectrode was calibrated in standard solutions of known $\mathrm{pH}(\mathrm{pH} 8.05,7.02,6.2$; calibration solution containing $150 \mathrm{mM} \mathrm{NaCl}+40 \mathrm{mM}$ HEPES). A salinefilled glass capillary electrode $(20 \mu \mathrm{m}$ outside tip diameter) was lowered $800-1000 \mu \mathrm{m}$ deep into the cerebral cortex to serve as reference for the $\mathrm{pH}$ sensitive electrode, and to record DC potential. The tips of the two electrodes were positioned as near as possible. $\mathrm{An} \mathrm{Ag} / \mathrm{AgCl}$ electrode implanted subcutaneously in the neck served as common ground. Microelectrodes were connected to a custom-made dualchannel high input impedance electrometer (including AD549LH, Analog Devices, Norwood, MA, USA) via $\mathrm{Ag} / \mathrm{AgCl}$ leads. The voltage signal recorded by the reference electrode was subtracted from that of the $\mathrm{pH}$ sensitive microelectrode by dedicated differential amplifiers and associated filter modules (NL106 and NL125, NeuroLog System, Digitimer Ltd, United Kingdom), which yielded potential variations related to changes in extracellular $\left[\mathrm{H}^{+}\right]$. The recorded signals were then forwarded to an analog-to-digital converter (MP 150, Biopac Systems, Inc). Electric signals were continuously acquired at a sampling frequency of $1 \mathrm{kHz}$. Extracellular $\mathrm{pH}$ changes were expressed in $\mathrm{mV}$ to be translated to $\mathrm{pH}$ units offline, using least squares linear regression.

SD-associated changes in local CBF were recorded using LaserDoppler flowmetry (LDF) by a Laser-Doppler needle probe (Probe 403 connected to PeriFlux 5000; Perimed AB, Sweden). The probe was positioned right above the cortical surface at the penetration site of the glass capillary electrodes with a micromanipulator, avoiding any large pial vessels. The signal was digitized and acquired, together with the DC potential and pH signals essentially as described above (MP 150 and AcqKnowledge 4.2.0, Biopac Systems, Inc. USA). The completed preparation was enclosed in a Faraday cage.

\subsection{Pharmacological treatment and experimental protocol}

Chitosan nanoparticle suspension - either loaded with nimodipine (an L-type voltage-gated calcium channel blocker), or devoid of the pharmacon (i.e. vehicle) - was prepared in aCSF according to Janovák et al. (2018). The nanoparticle suspension with encapsulated drug was expected to release nimodipine in response to a $\mathrm{pH}$ shift from physiological ( $\sim$ pH 7.35 ) to acidic ( $\sim$ pH 6.75 ) (Janovák et al., 2018). The pharmacological treatment was applied to rats with ipsilateral cranial windows only $(n=18)$. The rostral cranial window was incubated with the nanoparticle suspension including nimodipine at a concentration found previously effective when given in solution (Szabó et al., 2019) $(100 \mu M ; n=10)$ or vehicle $(n=8)$. Suspensions were refreshed every 10 min until the termination of the experiment. The craniotomies in preparations with bilateral cranial windows were regularly irrigated with aCSF alone $(n=4)$. Animal selection for treatment was random by alternating treatment as the experimental work proceeded.

After a baseline period of $15 \mathrm{~min}$, the suspension was washed to the brain surface and refreshed every $10 \mathrm{~min}$. Fifteen minutes later, incomplete, global forebrain ischemia was induced by occluding both common carotid arteries permanently ("2-vessel occlusion", 2VO). Occluders were pulled on until resistance was felt and were fixed in place. Successful 2VO was confirmed by an immediate, sharp drop of the LDF-signal displayed live. Fifteen minutes after 2VO onset, three SD events were evoked by placing a $1 \mathrm{M} \mathrm{KCl}$-soaked cotton ball on the exposed surface at an inter-SD interval of $15 \mathrm{~min}$. The cotton ball was removed immediately after the successful elicitation of each SD.

In some rats equipped with bilateral craniotomies $(n=3)$, aCSF was applied to one hemisphere, and nanoparticle suspension (i.e. vehicle) to the other, and $2 \mathrm{VO}$ was subsequently not imposed. This allowed the later evaluation of potential microglia activation by the direct exposure of the cerebral cortex to chitosan nanoparticles. Like in the $2 \mathrm{VO}$ rats, aCSF or the nanoparticle suspension were refreshed every $10 \mathrm{~min}$ until the termination of the experiments.

\subsection{Histology}

At the end of the experimental protocol, $1-1.5 \mathrm{~h}$ after ischemia induction, animals $(\mathrm{n}=16)$ were transcardially perfused in deep anesthesia with physiological saline followed by $4 \%$ paraformaldehyde (PFA). The brains were removed and postfixed overnight in 4\% PFA. Coronal forebrain sections of $20 \mu \mathrm{m}$ thickness were cut with a vibratome (Leica VT 1000S; Leica Microsystems, Wetzlar, Germany). Microglia were labeled with Iba1 (rabbit anti- Iba-1 primary antibody, 1:3000, 019-19741, Fujifilm Wako Chemicals Europe GmbH, Neuss, Germany) in order to explore whether the experimental procedures or the topical application of the nanoparticle suspension by itself induced microglia activation. To estimate neuronal loss due to SD, and neuroprotection offered by nimodipine, neurons in free floating slices were labeled for the marker NeuN with immunohistochemistry (rabbit antiNeuN primary antibody; 1:300, ab177487, AbCam, Cambridge, UK). Endogenous peroxidase activity was blocked with $5 \% \mathrm{H}_{2} \mathrm{O}_{2}$, the nonspecific protein binding sites were blocked with $5 \%$ normal goat serum (Merck, Kenilworth, New Jersey, USA) and the slices were permeabilized with Triton X-100 (Merck, Kenilworth, New Jersey, USA). Color reaction was developed with a Polink-2 Plus HRP Detection Kit for rabbit primary antibody with DAB (diaminobenzidine) chromogen (GBI Labs, Bothell, WA, USA). The slices were mounted on microscopic slides with Eukit ${ }^{\circledR}$ (Merck, Kenilworth, New Jersey, USA) and digitally recorded with a microscope slide scanner (Zeiss Mirax Midi Slide Scanner, Carl Zeiss MicroImaging GmbH, Jena, Germany) operated by a CaseViewer software (3D Histech Ltd., Budapest, Hungary). The slides were evaluated with ImageJ (Wayne Rasband, NIH, Bethesda, USA) software.

Microglial activation was characterized with a ramification index calculated according to previously established principles (Faulkner et al., 2011; Varga et al., 2018). In each animal, 3 coronal brain slices were selected for the analysis. In each slice, 3 photomicrographs were taken at 20x magnification along the depth of the parietal cortex in both hemispheres. A $126 \times 126 \mu \mathrm{m}$ grid was placed on each photomicrograph. Microglial branches/grid intersections (B) as well as microglial cell bodies within the grid (CBD) were counted manually with the Cell Counter plugin of ImageJ. The ramification index (RI) was calculated according to the following formula: $\mathrm{RI}=\mathrm{B} 2 / \mathrm{CBD}$. Since activated microglia are characterized by the retraction of their processes (i.e. amoeboid shape), the high ramification index corresponds to 
the resting state of microglia, while low ramification index reflects microglial activation.

Neuronal loss in the ipsi- and contralateral parietal cortex was characterized by the estimation NeuN-positive immunolabeling in a cortical area of a standard size. In each animal, 3 coronal brain slices were selected for the analysis. In each slice, 2 photomicrographs were taken at $5 \mathrm{x}$ magnification along the depth of the parietal cortex in both hemispheres. After masking binary images in ImageJ, the relative surface covered by NeuN-positive cell bodies was expressed.

\subsection{Data processing and analysis}

All variables (i.e., extracellular $\mathrm{pH}$, DC potential, LDF signal and MABP) were simultaneously acquired, displayed live, stored and analyzed using a personal computer equipped with a dedicated software (AcqKnowledge 4.2 for MP150, Biopac Systems, Inc., USA). For offline analysis, all variables were down sampled to $1 \mathrm{~Hz}$. Full data analysis was conducted for animals whose cerebrocortical tissue $\mathrm{pH}$ varied in the physiological range prior to the application of nanoparticles and during baseline $(\mathrm{n}=9)$.

Data were evaluated separately for the first SD (SD1), and recurrent SD (rSD) events, because of the differences in the kinetics of the SDassociated $\mathrm{CBF}$ response. Changes in local $\mathrm{CBF}$ were expressed relative to baseline by using the average $\mathrm{CBF}$ value preceding ischemia induction $(100 \%)$ and the mean recorded biological zero obtained after terminating the experiment $(0 \%)$ as reference points. The SD-associated hyperemia was then characterized by; (i) the amplitude of the peak hyperemia, (ii) duration of peak hyperemia at half amplitude and (iii) the magnitude (i. e. area under the curve, AUC) of the hyperemic response. SDs were analyzed by the following parameters: (i) amplitude of depolarization, (ii) duration of depolarization at half amplitude, (iii) AUC of the negative DC shift, (iv) rate of depolarization and (v) repolarization. Extracellular pH signal indicative of SD was characterized by (i) amplitude of the transient acidosis, (ii) duration at half amplitude, (iii) AUC of the $\mathrm{pH}$ response, and (iv) rate of acidosis and (v) recovery.

All recordings were first screened for events suitable for comprehensive analysis. Animals with alkalotic baseline brain pH over 7.5 were excluded from the analysis.

Data are given as mean \pm standard deviation (stdev). The software SPSS was used for statistical analysis (IBM SPSS Statistics for Windows, Version 22.0, IBM Corp.). A repeated measures, a one-way or a two-way analysis of variance (ANOVA) model was used, dependent on the type of data set. Levels of significance were defined as $p<0.05^{*}$. Distinct statistical methods are provided in detail in each Figure legend.

\section{Results}

\subsection{Evidence for drug release from nanoparticles}

Variables determined with arterial blood gas analysis were in the physiological range prior to the initiation of the experimental protocol $\left(\mathrm{pO}_{2}=144.4 \pm 24.4 \mathrm{mmHg}, \quad \mathrm{pCO}_{2}=39.8 \pm 9.9 \mathrm{mmHg}, \quad\right.$ blood $\mathrm{pH}=7.36 \pm 0.03$ ), with a shift to higher $\mathrm{pCO}_{2}$ and lower $\mathrm{pH}$ values $45-50 \mathrm{~min}$ after ischemia onset $\left(\mathrm{pO}_{2}=128.0 \pm 29.3 \mathrm{mmHg}\right.$, $\mathrm{pCO}_{2}=48.7 \pm 14.2 \mathrm{mmHg}$, blood $\left.\mathrm{pH}=7.28 \pm 0.06\right)$.

Nimodipine in solution, applied to the brain surface as done here, had been shown to increase local CBF significantly (Szabó et al., 2019). CBF elevation was, therefore, taken as a reliable read-out of the efficacy of nimodipine treatment, and was expected to confirm drug release from nanoparticles. In the current experiments, local CBF remained level during the incubation period, prior to ischemia onset $(99.2 \pm 2.6$ vs. $99.9 \pm 3.0 \%, 30 \mathrm{~min}$ after vs. before the application of nimodipine associated to nanoparticles), in the face of invariable tissue $\mathrm{pH}(\mathrm{pH}$ $7.29 \pm 0.22$ vs. $7.28 \pm 0.18,30 \mathrm{~min}$ after vs. before the application of nimodipine associated to nanoparticles) ((a) and (b) in Fig. 1). Ischemia induction produced a sharp drop of CBF to $29.4 \pm 10.2 \%$, and an acidic tissue $\mathrm{pH}$ shift to $7.06 \pm 0.30$ ((c) in Fig. 1). From this point on, CBF sampled prior to SD events increased in the nimodipine group, and was higher than in the vehicle group, particularly prior to rSDs (47.8 \pm 23.7 vs. $29.3 \pm 6.96 \%$, nimodipine vs. vehicle) ((f) in Fig. 1), which were triggered subsequent to the transient reduction of tissue $\mathrm{pH}$ to $6.71 \pm 0.29$ with SD1 ((e) in Fig. 1). At the same time, the expected release of nimodipine from the nanoparticles did not exert any discernible impact on MABP (e.g. $96.7 \pm 14.3$ vs. $92.0 \pm 10.9 \mathrm{mmHg}$, nimodipine vs. vehicle, after ischemia induction - and thus the initiation of drug release) ((d) in Fig. 1).

\subsection{Spreading depolarization}

Spreading depolarization events were experimentally triggered under global forebrain ischemia to evaluate the potential impact of nimodipine delivered with nanoparticles on the kinetics of SD, and the associated tissue $\mathrm{pH}$ variation and $\mathrm{CBF}$ response (Figs. 2-4). The first SD (SD1) and the recurrent SDs (rSD) were analyzed apart, because of known differences in the kinetics of SD associated CBF response and tissue pH variation (Farkas et al., 2008; Menyhárt et al., 2017).

SD occurrence was confirmed by the transient negative shift of the DC potential (Fig. 2A). The analysis of the DC potential signature of SDs demonstrated that nimodipine applied in the nanoparticle suspension
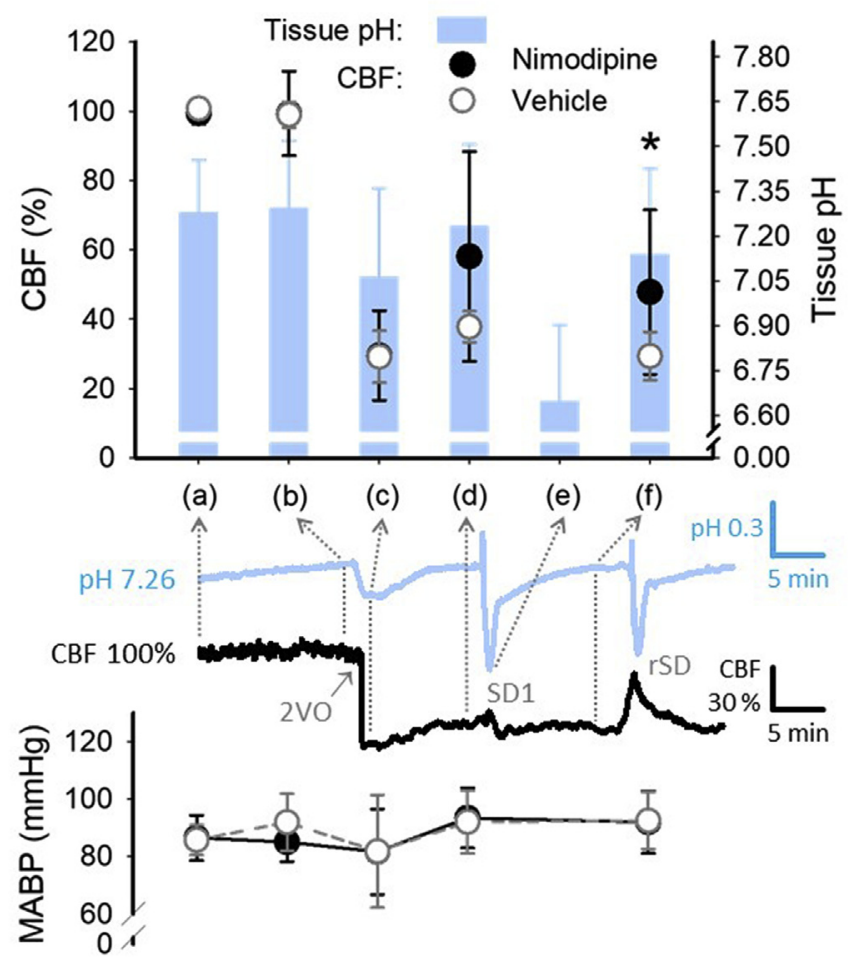

Fig. 1. Variation of baseline cerebral blood flow (CBF; upper scatter plot with y axis to the left) with respect to tissue $\mathrm{pH}$ (bar chart with y axis to the right), and mean arterial pressure (MABP; lower scatter plot) at selected points of the experimental protocol: (a) before treatment initiation; (b) after treatment initiation; (c) minimum after ischemia induction; (d) prior to the first spreading depolarization (SD1); (e) $\mathrm{pH}$ minimum with SD1; (f) prior to recurrent SD (rSD) events. Note that CBF becomes higher in the nimodipine group compared to the vehicle group following the tissue $\mathrm{pH}$ drop with ischemia induction. Representative traces under the bar chart (tissue $\mathrm{pH}$ : blue, CBF: black) obtained from an animal treated with nimodipine show typical signal variation over the experimental protocol. Data are given as mean \pm stdev. Statistical analysis relied on one-way analysis of variance (ANOVA) paradigm for CBF and tissue $\mathrm{pH}$, and a repeated measures model for MABP. The level of significance was defined as $\mathrm{p}<0.05^{*}$. (For interpretation of the references to colour in this figure legend, the reader is referred to the Web version of this article.) 
A

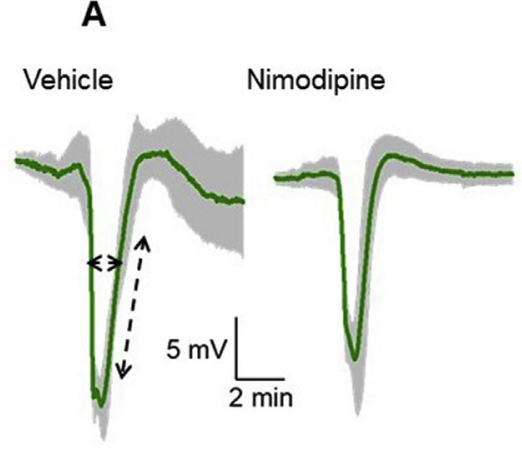

B

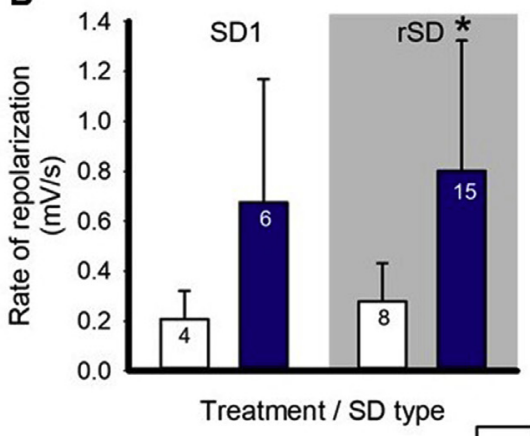

C

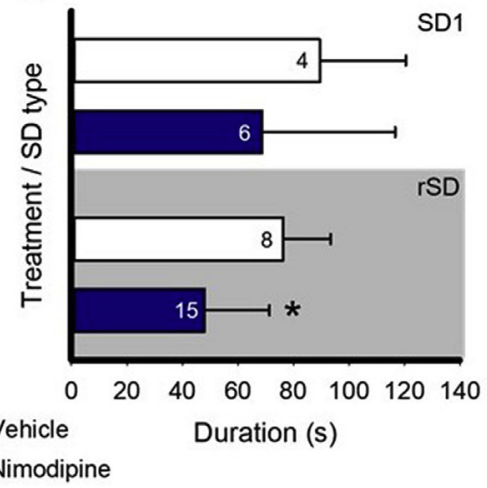

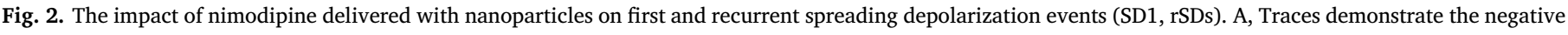

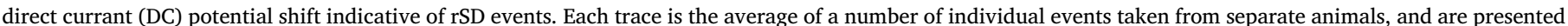

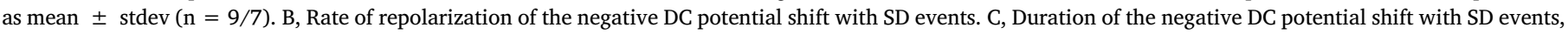

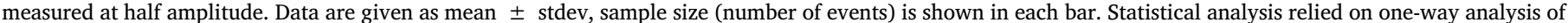
variance (ANOVA) paradigm. The level of significance was defined as $\mathrm{p}<0.05^{*}$.
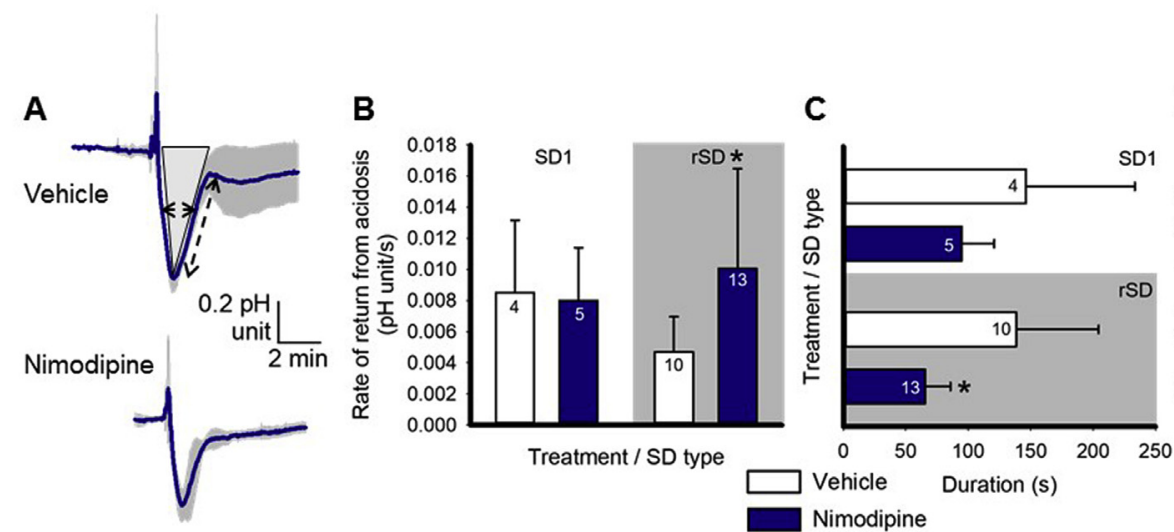

D

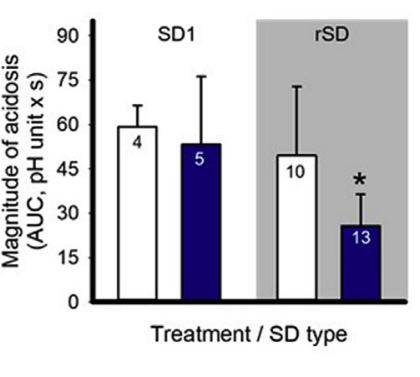

Fig. 3. The impact of nimodipine delivered with nanoparticles on the tissue $\mathrm{pH}$ response related to the first and recurrent spreading depolarization events (SD1, rSDs). A, Traces demonstrate the kinetics of the $\mathrm{pH}$ response to rSD events. Each trace is the average of a number of individual events taken from separate animals, and are presented as mean \pm stdev $(n=4 / 6)$. B, Rate of return from tissue acidosis. C, Duration of tissue acidosis taken at half amplitude. D, Magnitude (i. e. area under the curve, AUC) of tissue acidosis. Data are given as mean \pm stdev, sample size (number of events) is shown in each bar. Statistical analysis relied on one-way analysis of variance (ANOVA) paradigm. The level of significance was defined as $\mathrm{p}<0.05^{*}$.

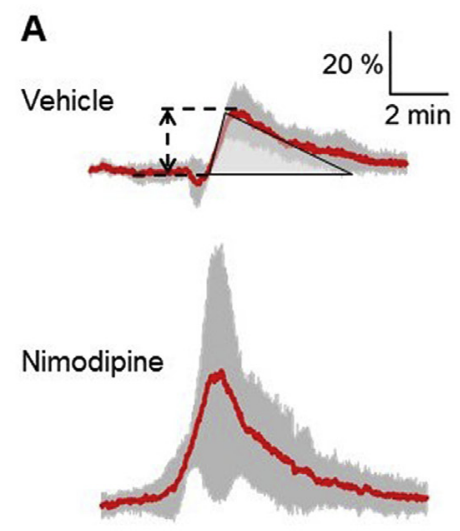

B

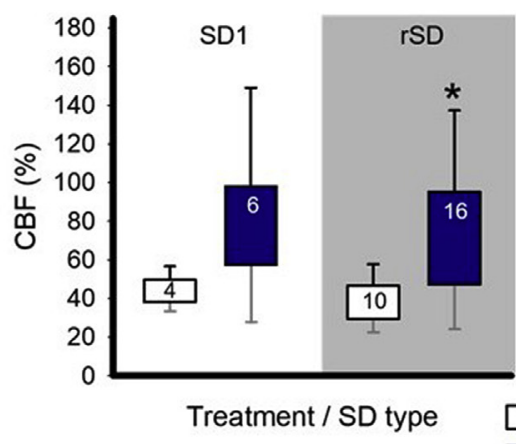

C

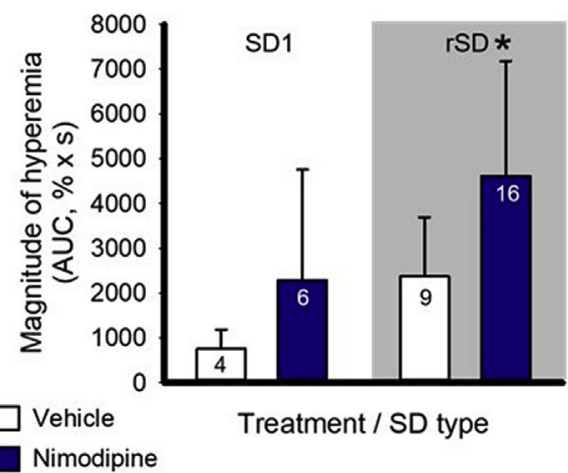

Fig. 4. The impact of nimodipine delivered with nanoparticles on the cerebral blood flow (CBF) response to the first and recurrent spreading depolarization events (SD1, rSDs). A, Traces demonstrate the kinetics of CBF response to rSD events. Each trace is the average of a number of individual events, and are presented as mean $\pm \operatorname{stdev}(n=9 / 14)$. B, Amplitude of peak hyperemia. The base of each bar in the chart is set to the CBF level preceding SD events. C, Magnitude (i. e. area under the curve, AUC) of peak hyperemia. Data are given as mean \pm stdev, sample size (number of events) is shown in each bar. Statistical analysis relied on oneway analysis of variance (ANOVA) paradigm. The level of significance was defined as $\mathrm{p}<0.05^{*}$. 
facilitated the rate of repolarization of rSD events in particular $(0.8 \pm 0.523$ vs. $0.279 \pm 0.153 \mathrm{mV} / \mathrm{s}$, nimodipine vs. vehicle) (Fig. 2B). Accordingly, the duration of rSDs shortened significantly with respect to control $(48.07 \pm 23.29$ vs. $76.25 \pm 17.2 \mathrm{~s}$, nimodipine vs. vehicle) (Fig. 2C).

Tissue $\mathrm{pH}$ variations associated with SD events started with a rapid, short alkaline shift followed by a longer-lasting, dominant, transient acidosis (Fig. 3A) (Menyhárt et al., 2017). Tissue pH did not fully recover and remained typically mildly acidic after SD1 compared to later rSDs (pH $7.14 \pm 0.29$ vs. $7.23 \pm 0.28$, prior to rSDs vs. prior to SD1), but the difference was statistically not significant. Nimodipine treatment had no measurable impact on the initial alkaline shift, but it modified the kinetics of the subsequent transient acidosis. As such, nimodipine delivered by nanoparticles facilitated the rate of return from the acidic shift with rSDs (0.01 \pm 0.006 vs. $0.005 \pm 0.002 \mathrm{pH}$ unit/s, nimodipine vs. vehicle) (Fig. 3B) and shortened the duration of acidosis with rSDs ( $65.46 \pm 20.2$ vs. $138.3 \pm 66.07 \mathrm{~s}$, nimodipine vs. vehicle) (Fig. 3C). As a consequence, the magnitude of acidosis expressed as area under the curve was substantially reduced in the nimodipine compared to vehicle group $(25.75 \pm 10.69$ vs. $49.46 \pm 23.38 \mathrm{pH}$ unit*s, nimodipine vs. vehicle) (Fig. 3C).

The SD related CBF response in anesthetized rats includes an initial transient hypoperfusion, followed by a peak hyperemia and is concluded by a long lasting oligemia (Ayata and Lauritzen, 2015; Menyhárt et al., 2017; Szabó et al., 2019). The initial hypoperfusion proved to be detectable only occasionally (Fig. 4A), therefore the analysis focused on the peak hyperemic element of the CBF response (Fig. 4). As expected, nimodipine delivered by nanoparticles significantly enhanced the amplitude (48.15 \pm 42.04 vs. $17.29 \pm 11.03 \%$, nimodipine vs. vehicle) and the magnitude of peak hyperemia in response to rSDs (4604.43 \pm 2572.3 vs. $2368.05 \pm 1324.71 \%$ *s, nimodipine vs. vehicle) (Fig. 4B-C).

\subsection{Histology}

In order to explore whether the chitosan nanoparticles used here might trigger neuroinflammatory reaction (a potential unfavorable side effect of the drug delivery approach), we estimated microglial activation in immuno-stained brain sections. Microglia immunolabeled for Iba1 appeared to be activated in the cerebral cortex ipsilateral to the initiation of SD, as shown by their sparser processes and rounded, amoeboid shape (Fig. 5A). Microglia activation was quantitatively expressed by a ramification index (Varga et al., 2018) representing the density of microglial processes. The ramification index was remarkably reduced in the ipsilateral compared to the contralateral somatosensory cortex (e.g. $398 \pm 203$ vs. $1118 \pm 300$, ipsi-vs. contralateral to SD induction in the vehicle group) (Fig. $5 \mathrm{~A}$ ). The trepanation procedure activated microglia (480 \pm 211 vs. $740 \pm 394$, trepanated vs. nontrepanated contralateral to SD induction; $\mathrm{p}<0.048^{*}$ ), but the hemisphere-specific reduction of the ramification index was also attributed to SD, because it was clearly observed in rats with bilateral craniotomy, as well $(201 \pm 102$ vs. $483 \pm 244$, ipsi-vs. contralateral to SD induction; $\left.\mathrm{p}<0.002^{* *}\right)$. The application of the nanoparticle suspension alone (vehicle), or incorporating nimodipine did not reduce the ramification index any further compared to aCSF-rinsed preparations of cerebral ischemia $(443 \pm 208$ vs. $398 \pm 203$ vs. $284 \pm 107$, nimodipine vs. vehicle vs. aCSF; ipsilateral) (Fig. 5A). In naïve rats equipped with bilateral craniotomy, one hemisphere treated with aCSF and the other with vehicle (i.e. nanoparticle suspension), the microglia ramification index was also found to be similar under the two conditions (389 \pm 126 vs. $475 \pm 172$, vehicle vs. aCSF, $\mathrm{p}<0.247)$. Thus, the administration of nanoparticles on the cortical surface did not produce a detectable potentiation of microglia activation additional to any of the interventions (i.e. trepanation or ischemia induction).

We labeled viable neurons with NeuN immunocytochemistry to estimate (i) the degree of early neurodegeneration SD might cause in the acute phase of global forebrain ischemia, and (ii) the potential neuroprotection achieved by nimodipine (Fig. 5B). We screened the somatosensory cortex (i.e. over the striatum) distant to the site of SD elicitation (i.e. over the hippocampus), with the aim to exclude areas from the analysis, in which neurodegeneration might have been caused by topical $\mathrm{KCl}$ application to trigger SD. In some animals, the reduced
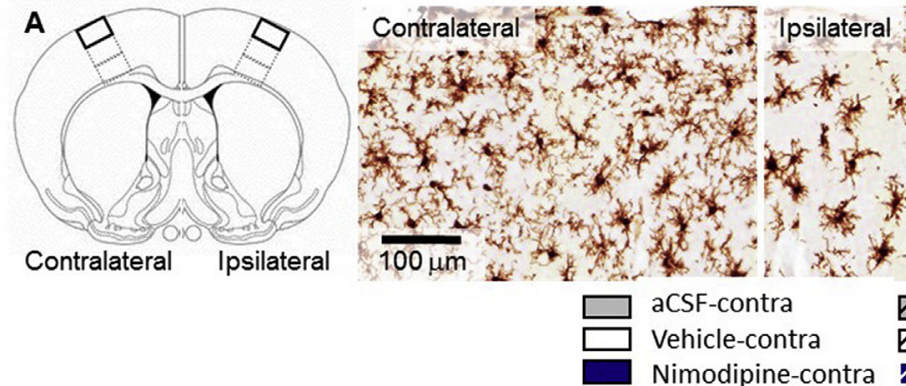

Nimodipine-contr
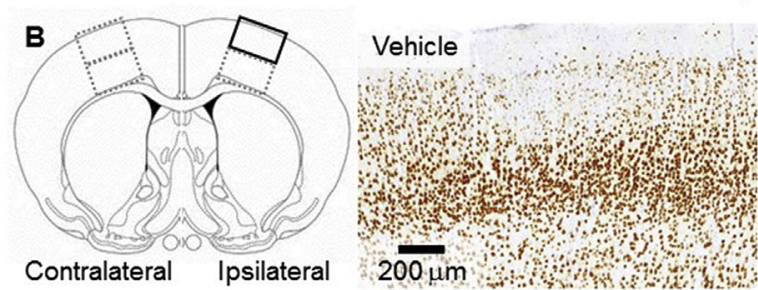
Nimodipine (1)
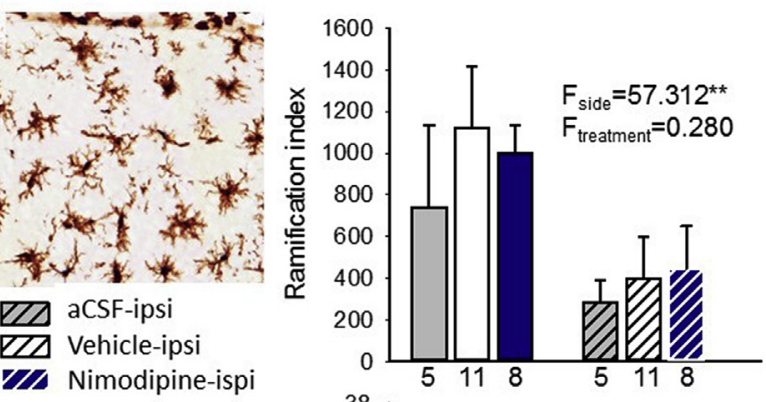

Contralateral

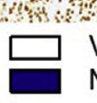

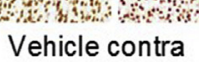

Nimodipine contra ne
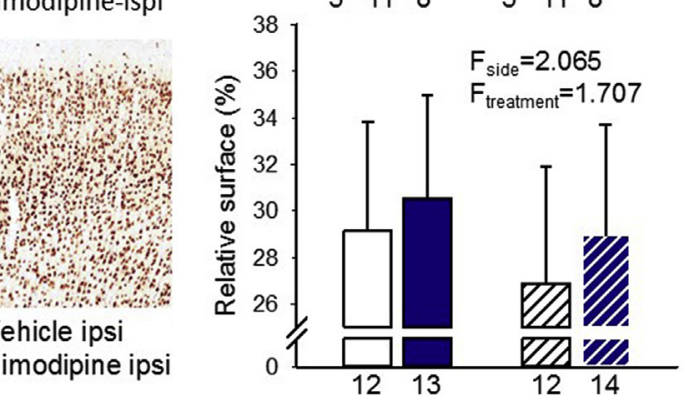

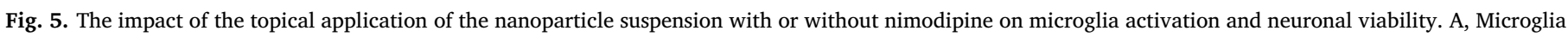

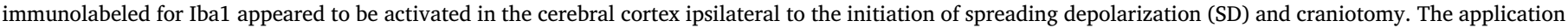

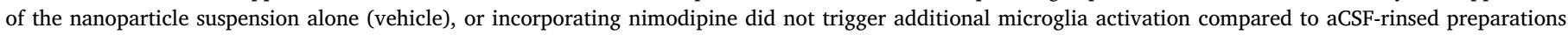

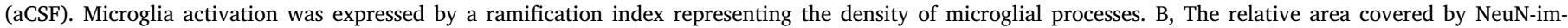

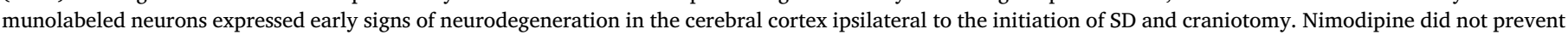

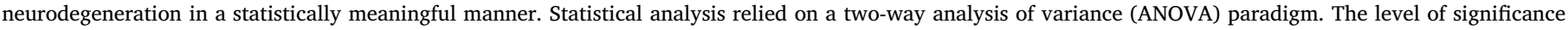
was defined as $\mathrm{p}<0.05^{*}$. 
relative area covered by NeuN-immunolabeled neurons indicated early neurodegeneration in the cerebral cortex ipsilateral to the initiation of SD (Fig. 5B), albeit the quantitative analysis did not reveal significant SD-related neuron loss $(26.9 \pm 5.0$ vs. $29.1 \pm 4.7 \%$, ipsi-vs. contralateral in the vehicle group) (Fig. 5B). NeuN labeling was not enhanced in the nimodipine-treated group in a statistically meaningful manner $(29.0 \pm 4.8$ vs. $26.9 \pm 5.0 \%$, nimodipine vs. vehicle in the ipsilateral cortex) (Fig. 5B).

\section{Discussion}

Nanomedicine, the application of nanotechnology with therapeutical purpose offers drug delivery targeted selectively to desired sites, and with the potential of controlled drug release (Boulaiz et al., 2011; Patra et al., 2018). Nimodipine inhibits calcium influx to vascular smooth muscle cells through L-type voltage gated calcium channels and causes vasodilation. In addition, nimodipine blocks neuronal L-type voltage gated calcium channels, as well, mitigates neuronal calcium overload, and achieves neuroprotection under ischemic stress (Scriabine et al., 1989). Here we set out to explore whether nanoparticles designed to release nimodipine in response to $\mathrm{pH}$ decreasing below the physiological range are effective in experimental cerebral ischemia. The experimental model used reproduces conditions typical of the ischemic penumbra (Astrup et al., 1977; Menyhárt et al., 2017), which is indicated by tissue perfusion ranging between 20 and $40 \%$, and tissue $\mathrm{pH}$ dropping to 6.9-7.1 after ischemia induction (Fig. 1).

The vasodilator nimodipine (washed on the brain surface in solution and at the concentration used here) was previously found to produce a progressive baseline CBF increase during drug incubation (Szabó et al., 2019). In the present study, nimodipine associated to $\mathrm{pH}$-responsive nanoparticles did not achieve CBF elevation prior to ischemia induction, when tissue $\mathrm{pH}$ was physiological (Fig. 1), which confirms that nimodipine was not dissociated from the nanoparticles at near neutral tissue $\mathrm{pH}$. Subsequent to the induction of ischemia and the related transient tissue acidosis, baseline $\mathrm{CBF}$ was found to be higher in the nimodipine compared to the vehicle group, which is consistent with the known cerebrovascular action of nimodipine (Harper et al., 1981), and is interpreted as the in vivo verification of $\mathrm{pH}$-sensitive drug release (Janovák et al., 2018). By the topical application of nimodipine in solution, we recently found that nimodipine inhibited SD evolution, possibly by blocking calcium entry to nerve cells, and augmented hyperemia in response to SD in the ischemic rat cerebral cortex (Szabó et al., 2019). The present findings (Figs. 2 and 4) are fully consistent with the data previously gathered, and substantiate the efficacy of drug delivery with $\mathrm{pH}$-responsive nanoparticles.

To further evaluate the neuroprotective potential of the treatment, we labeled viable neurons with NeuN immunocytochemistry and quantified neuronal density in the cerebral cortex. At this early time point after ischemia induction, we observed in some animals less dense NeuN staining in the parietal cortex where SDs propagated, compared to the contralateral hemisphere exposed to ischemia alone. It has been previously demonstrated that repetitive SDs superimposed on focal cerebral ischemia created by middle cerebral artery occlusion in the rat exacerbated neurodegeneration (Back et al., 1996). Our data stand in line with these earlier experimental observations, and support the view that recurrent SDs represent a key mechanism of ischemic cellular injury (Dreier, 2011; Dreier and Reiffurth, 2015; Hartings et al., 2017). Nimodipine did not rescue neurons to a statistically meaningful degree at this endpoint. It is considered as a limitation of the current experimental paradigm that the nature of the surgical procedures did not favor the follow-up of histological alterations $24 \mathrm{~h}$ or days after the primary impact, when ischemia-related neuronal loss and signs of potential neuroprotection may become more obvious.

The use of $\mathrm{pH}$-sensitive microelectrodes in our preparation offered the unique opportunity to assess the impact of nimodipine on the SDassociated transient tissue acidosis (Fig. 3), an action of nimodipine not screened before. The SD-related acidosis, which has been linked to the accumulation of lactate (Mutch and Hansen, 1984; Scheller et al., 1992) was previously contemplated to exacerbate ischemic injury and jeopardize the survival of penumbra tissue (Menyhárt et al., 2017), therefore its inhibition is expected to be beneficial. Here we have observed that nimodipine potently reduced the degree of SD-related acidosis. Similarly, intravenously administered nimodipine was shown to moderate tissue acidosis in experimental focal cerebral ischemia (Berger and Hakim, 1988; Bielenberg et al., 1990), which was attributed to the direct facilitation of metabolic lactate clearance, independent of perfusion rate (Bielenberg et al., 1987; Berger and Hakim, 1988). It is thus conceivable that the inhibition of calcium entry to neurons by nimodipine (Scriabine et al., 1989) may support mitochondrial function and oxidative lactate degradation (Bielenberg et al., 1987), which may reduce the acid load associated with SD, as seen here. It is also reasonable to argue that the shorter duration of SDrelated acidosis due to nimodipine (Fig. 3C) is consistent with the shorter duration of SD itself (Fig. 2C), and the primary effect of nimodipine was the inhibition of SD, causing a secondary reduction of the associated tissue acidosis.

Finally, we intended to examine whether chitosan nanoparticles may induce a neuroimmune response at the brain tissue in contact with the nanoparticles. Chitosan, a derivative of chitin, is a biocompatible, biodegradable, natural polysaccharide, which has been considered as immune adjuvant in cancer therapy (Li et al., 2013; Carroll et al., 2016). Microglia form the active immune defense of the brain, and their reaction to inflammatory stimuli is accompanied by their typical morphological alteration (i.e. retraction of processes, amoeboid form). We, therefore, labeled microglia to estimate their potential activation by chitosan nanoparticles in our experimental model. This also offered the opportunity to examine whether SD propagating over ischemic tissue potentiates the ischemia-related activation of microglia, since accumulating evidence suggest that repetitive SDs activate microglia in intact brain tissue (Shibata and Suzuki, 2017). Our data reveal that recurrent SDs do potentiate microglia activation in the ischemic cerebral cortex, in line with previous observations made in the intact cortex (Gehrmann et al., 1993; Caggiano and Kraig, 1996; Shibata and Suzuki, 2017). The application of chitosan nanoparticle suspension to the exposed cortical surface did not enhance microglia activation with respect to aCSF rinsed preparations in our experiments, which suggests that the chitosan nanoparticles themselves did not trigger a detectable local immune reaction in the cerebral cortex.

In summary, the data generated here support the concept that tissue acidosis linked to cerebral ischemia can be employed as a trigger for targeted drug delivery. In addition, nimodipine-mediated vasodilation and neuroprotection can be achieved by $\mathrm{pH}$-responsive chitosan nanoparticles applied directly to the brain surface.

With these data in hand, the ultimate goal of our future work is to conceive a feasible approach for the systemic administration of the nimodipine-loaded nanoparticle suspension with the purpose of neuroprotection in experimental stroke, which could be translated realistically to clinical settings. Even though chitosan does not penetrate the brain parenchyma via the intact blood-brain barrier (BBB), considering the use of chitosan nanoparticles may be especially relevant for three reasons. First, chitosan can be functionalized with antibodies that recognize specific receptors (e.g. transferrin receptors) on BBB endothelial cells to internalize the nanospheres. This approach has been used successfully to deliver caspase inhibitors across the BBB under experimental conditions (Aktaş et al., 2005; Yemişci et al., 2012). Second, the breakdown of BBB (Jiang et al., 2018) - the loosening of tight junctions or the non-selective enhancement of transendothelial vesicular transport - may also give way to chitosan entry to the nervous tissue along with plasma extravasation in cerebral ischemia. Interestingly, SD itself has been shown to increase the permeability of the BBB (Sadeghian et al., 2018), and facilitate drug delivery to the brain (Cottier et al., 2018). These data encourage the intravenous 
administration of the drug carrier nanoparticles. Finally, much research effort has been dedicated to evaluate the efficacy of targeting drugs to the brain by intranasal chitosan administration, which offers another alternative route (Casettari and Illum, 2014). Taken together, our current data may form a basis for the development of smart drug delivery systems selectively targeted to the sensitive penumbra zone in ischemic stroke.

\section{Declaration of competing interest}

The authors report no competing interests.

\section{Acknowledgements}

This work was supported by grants from the National Research Development and Innovation Office of Hungary (No. K120358, K111923 and PD128821); the Ministry of Human Capacities of Hungary (No. UNKP-18-3-I-SZTE-26) the Szeged Scientists Academy Program of the Foundation for the Future of Biomedical Sciences in Szeged, implemented with the support of the Ministry of Human Capacities of Hungary (No. 34232-3/2016/INTFIN); the Economic Development and Innovation Operational Programme in Hungary co-financed by the European Union and the European Regional Development Fund (No. GINOP-2.3.2-15-2016-00060); the EU-funded Hungarian grant No. EFOP-3.6.1-16- 2016-00008, and the Ministry of Human Capacities, Hungary grant 20391-3/2018/FEKUSTRAT.

\section{Appendix A. Supplementary data}

Supplementary data to this article can be found online at https:// doi.org/10.1016/j.neuropharm.2019.107850.

\section{References}

Aktas, Y., Yemisci, M., Andrieux, K., Gürsoy, R.N., Alonso, M.J., Fernandez-Megia, E. Novoa-Carballal, R., Quiñoá, E., Riguera, R., Sargon, M.F., Celik, H.H., Demir, A.S., Hincal, A.A., Dalkara, T., Capan, Y., Couvreur, P., 2005. Development and brain delivery of chitosan-PEG nanoparticles functionalized with the monoclonal antibody OX26. Bioconjug. Chem. 16 (6), 1503-1511.

Astrup, J., Symon, L., Branston, N.M., Lassen, N.A., 1977. Cortical evoked potential and extracellular $\mathrm{K}+$ and $\mathrm{H}+$ at critical levels of brain ischemia. Stroke 8 (1), 51-57.

Ayata, C., Lauritzen, M., 2015. Spreading depression, spreading depolarizations, and the cerebral vasculature. Physiol. Rev. 95 (3), 953-993.

Back, T., Ginsberg, M.D., Dietrich, W.D., Watson, B.D., 1996. Induction of spreading depression in the ischemic hemisphere following experimental middle cerebral artery occlusion: effect on infarct morphology. J. Cereb. Blood Flow Metab. 16 (2), 202-213.

Balami, J.S., Hadley, G., Sutherland, B.A., Karbalai, H., Buchan, A.M., 2013. The exact science of stroke thrombolysis and the quiet art of patient selection. Brain 136 (Pt 12), 3528-3553.

Berger, L., Hakim, A.M., 1988. Calcium channel blockers correct acidosis in ischemic rat brain without altering cerebral blood flow. Stroke 19 (10), 1257-1261.

Bielenberg, G.W., Burniol, M., Rösen, R., Klaus, W., 1990. Effects of nimodipine on infarct size and cerebral acidosis after middle cerebral artery occlusion in the rat. Stroke 21 (12 Suppl. 1), IV90-IV92.

Bielenberg, G.W., Haubruck, H., Krieglstein, J., 1987. Effects of calcium entry blocker emopamil on postischemic energy metabolism of the isolated perfused rat brain. J. Cereb. Blood Flow Metab. 7 (4), 489-496.

Boulaiz, H., Alvarez, P.J., Ramirez, A., Marchal, J.A., Prados, J., Rodríguez-Serrano, F., Perán, M., Melguizo, C., Aranega, A., 2011. Nanomedicine: application areas and development prospects. Int. J. Mol. Sci. 12 (5), 3303-3321.

Caggiano, A.O., Kraig, R.P., 1996. Eicosanoids and nitric oxide influence induction of reactive gliosis from spreading depression in microglia but not astrocytes. J. Comp. Neurol. 369 (1), 93-108.

Campbell, B.C.V., Donnan, G.A., Lees, K.R., Hacke, W., Khatri, P., Hill, M.D., Goyal, M., Mitchell, P.J., Saver, J.L., Diener, H.C., Davis, S.M., 2015. Endovascular stent thrombectomy: the new standard of care for large vessel ischaemic stroke. Lancet Neurol. 14 (8), 846-854.

Carlson, A.P., Abbas, M., Alunday, R.L., Qeadan, F., Shuttleworth, C.W., 2018. Spreading depolarization in acute brain injury inhibited by ketamine: a prospective, randomized, multiple crossover trial. J. Neurosurg. 25, 1-7.

Carroll, E.C., Jin, L., Mori, A., Muñoz-Wolf, N., Oleszycka, E., Moran, H.B.T., Mansouri, S., McEntee, C.P., Lambe, E., Agger, E.M., Andersen, P., Cunningham, C., Hertzog, P., Fitzgerald, K.A., Bowie, A.G., Lavelle, E.C., 2016. The vaccine adjuvant chitosan promotes cellular immunity via DNA sensor cGAS-STING-dependent induction of type I interferons. Immunity 44 (3), 597-608.

Casettari, L., Illum, L., 2014. Chitosan in nasal delivery systems for therapeutic drugs. J، Control. Release 190, 189-200.

Cottier, K.E., Galloway, E.A., Calabrese, E.C., Tome, M.E., Liktor-Busa, E., Kim, J., Davis, T.P., Vanderah, T.W., Largent-Milnes, T.M., 2018. Loss of blood-brain barrier integrity in a $\mathrm{KCl}$-induced model of episodic headache enhances CNS drug delivery. eNeuro 5 (4).

Dorhout Mees, S.M., Rinkel, G.J., Feigin, V.L., Algra, A., van den Bergh, W.M., Vermeulen, M., van Gijn, J., 2007. Calcium antagonists for aneurysmal subarachnoid haemorrhage. Cochrane Database Syst. Rev. 18 (3), CD000277.

Dreier, J.P., 2011. The role of spreading depression, spreading depolarization and spreading ischemia in neurological disease. Nat. Med. 17 (4), 439-447.

Dreier, J.P., Körner, K., Ebert, N., Görner, A., Rubin, I., Back, T., Lindauer, U., Wolf, T. Villringer, A., Einhäupl, K.M., Lauritzen, M., Dirnagl, U., 1998. Nitric oxide scavenging by hemoglobin or nitric oxide synthase inhibition by N-nitro-L-arginine induces cortical spreading ischemia when $\mathrm{K}+$ is increased in the subarachnoid space. J. Cereb. Blood Flow Metab. 18 (9), 978-990.

Dreier, J.P., Major, S., Manning, A., Woitzik, J., Drenckhahn, C., Steinbrink, J., Tolias, C., Oliveira-Ferreira, A.I., Fabricius, M., Hartings, J.A., Vajkoczy, P., Lauritzen, M., Dirnagl, U., Bohner, G., Strong, A.J., COSBID study group, 2009. Cortical spreading ischaemia is a novel process involved in ischaemic damage in patients with aneurysmal subarachnoid haemorrhage. Brain 132 (Pt 7), 1866-1881.

Dreier, J.P., Reiffurth, C., 2015. The stroke-migraine depolarization continuum. Neuron 86 (4), 902-922.

Dreier, J.P., Windmüller, O., Petzold, G., Lindauer, U., Einhäupl, K.M., Dirnagl, U., 2002. Ischemia triggered by red blood cell products in the subarachnoid space is inhibited by nimodipine administration or moderate volume expansion/hemodilution in rats. Neurosurgery 51 (6), 1457-1465 discussion 1465-1467.

Dreier, J.P., Woitzik, J., Fabricius, M., Bhatia, R., Major, S., Drenckhahn, C., Lehmann, T.N., Sarrafzadeh, A., Willumsen, L., Hartings, J.A., Sakowitz, O.W., Seemann, J.H., Thieme, A., Lauritzen, M., Strong, A.J., 2006. Delayed ischaemic neurological deficits after subarachnoid haemorrhage are associated with clusters of spreading depolarizations. Brain 129 (Pt 12), 3224-3237.

Du, J.Z., Mao, C.Q., Yuan, Y.Y., Yang, X.Z., Wang, J., 2014. Tumor extracellular acidityactivated nanoparticles as drug delivery systems for enhanced cancer therapy. Biotechnol. Adv. 32 (4), 789-803.

Etminan, N., Macdonald, R.L., Davis, C., Burton, K., Steiger, H.J., Hänggi, D., 2015 Intrathecal application of the nimodipine slow-release microparticle system eg-1962 for prevention of delayed cerebral ischemia and improvement of outcome after aneurysmal subarachnoid hemorrhage. Acta Neurochir. Suppl. 120, 281-286.

Farkas, E., Pratt, R., Sengpiel, F., Obrenovitch, T.P., 2008. Direct, live imaging of cortical spreading depression and anoxic depolarisation using a fluorescent, voltage-sensitive dye. J. Cereb. Blood Flow Metab. 28 (2), 251-262.

Faulkner, S., Bainbridge, A., Kato, T., Chandrasekaran, M., Kapetanakis, A.B., Hristova, M., Liu, M., Evans, S., De Vita, E., Kelen, D., Sanders, R.D., Edwards, A.D., Maze, M., Cady, E.B., Raivich, G., Robertson, N.J., 2011. Xenon augmented hypothermia reduces early lactate/ $\mathrm{N}$-acetylaspartate and cell death in perinatal asphyxia. Ann. Neurol. 70 (1), 133-150.

Fogelholm, R., Erilä, T., Palomäki, H., Murros, K., Kaste, M., 2000. Effect of nimodipine on final infarct volume after acute ischemic stroke. Cerebrovasc. Dis. 10 (3), 189-193.

Gehrmann, J., Mies, G., Bonnekoh, P., Banati, R., Iijima, T., Kreutzberg, G.W., Hossmann, K.A., 1993. Microglial reaction in the rat cerebral cortex induced by cortical spreading depression. Brain Pathol. 3 (1), 11-17.

Hänggi, D., Perrin, J., Eicker, S., Beseoglu, K., Etminan, N., Kamp, M.A., Heiroth, H.J., Bege, N., Macht, S., Frauenknecht, K., Sommer, C., Kissel, T., Steiger, H.J., 2012. Local delivery of nimodipine by prolonged-release microparticles-feasibility, effectiveness and dose-finding in experimental subarachnoid hemorrhage. PLoS One 7 (9) e42597.

Harper, A.M., Craigen, L., Kazda, S., 1981. Effect of the calcium antagonist, nimodipine, on cerebral blood flow and metabolism in the primate. J. Cereb. Blood Flow Metab. 1 (3), 349-356.

Hartings, J.A., Shuttleworth, C.W., Kirov, S.A., Ayata, C., Hinzman, J.M., Foreman, B., Andrew, R.D., Boutelle, M.G., Brennan, K.C., Carlson, A.P., Dahlem, M.A., Drenckhahn, C., Dohmen, C., Fabricius, M., Farkas, E., Feuerstein, D., Graf, R., Helbok, R., Lauritzen, M., Major, S., Oliveira-Ferreira, A.I., Richter, F., Rosenthal, E.S., Sakowitz, O.W., Sánchez-Porras, R., Santos, E., Schöll, M., Strong, A.J., Urbach, A., Westover, M.B., Winkler, M.K., Witte, O.W., Woitzik, J., Dreier, J.P., 2017. The continuum of spreading depolarizations in acute cortical lesion development: examining Leão's legacy. J. Cereb. Blood Flow Metab. 37 (5), 1571-1594.

Hertelendy, P., Varga, D.P., Menyhárt, Á., Bari, F., Farkas, E., 2019. Susceptibility of the cerebral cortex to spreading depolarization in neurological disease states: the impact of aging. Neurochem. Int. 127, 125-136.

Hertle, D.N., Dreier, J.P., Woitzik, J., Hartings, J.A., Bullock, R., Okonkwo, D.O., Shutter, L.A., Vidgeon, S., Strong, A.J., Kowoll, C., Dohmen, C., Diedler, J., Veltkamp, R., Bruckner, T., Unterberg, A.W., Sakowitz, O.W., Cooperative Study of Brain Injury Depolarizations (COSBID), 2012. Effect of analgesics and sedatives on the occurrence of spreading depolarizations accompanying acute brain injury. Brain 135 (Pt 8), 2390-2398.

Hossmann, K.A., 1996. Periinfarct depolarizations. Cerebrovasc. Brain Metab. Rev 8 (3), 195-208.

Janovák, L., Turcsányi, Á., Bozó, É., Deák, Á., Mérai, L., Sebők, D., Juhász, Á., Csapó, E., Abdelghafour, M.M., Farkas, E., Dékány, I., Bari, F., 2018. Preparation of novel tissue acidosis-responsive chitosan drug nanoparticles: characterization and in vitro release properties of $\mathrm{Ca} 2+$ channel blocker nimodipine drug molecules. Eur. J. Pharm. Sci. 123, 79-88. 
Jiang, X., Andjelkovic, A.V., Zhu, L., Yang, T., Bennett, M.V.L., Chen, J., Keep, R.F., Shi, Y., 2018. Blood-brain barrier dysfunction and recovery after ischemic stroke. Prog. Neurobiol. 163-164, 144-171.

Li, X., Min, M., Du, N., Gu, Y., Hode, T., Naylor, M., Chen, D., Nordquist, R.E., Chen, W.R., 2013. Chitin, chitosan, and glycated chitosan regulate immune responses: the novel adjuvants for cancer vaccine. Clin. Dev. Immunol. 2013, 387023.

Lückl, J., Lemale, C.L., Kola, V., Horst, V., Khojasteh, U., Oliveira-Ferreira, A.I., Major, S., Winkler, M.K.L., Kang, E.J., Schoknecht, K., Martus, P., Hartings, J.A., Woitzik, J., Dreier, J.P., 2018. The negative ultraslow potential, electrophysiological correlate of infarction in the human cortex. Brain 141 (6), 1734-1752.

Martínez-Vila, E., Guillén, F., Villanueva, J.A., Matías-Guiu, J., Bigorra, J., Gil, P., Carbonell, A., Martínez-Lage, J.M., 1990. Placebo-controlled trial of nimodipine in the treatment of acute ischemic cerebral infarction. Stroke 21 (7), 1023-1028.

Menyhárt, Á., Farkas, A.E., Varga, D.P., Frank, R., Tóth, R., Bálint, A.R., Makra, P., Dreier, J.P., Bari, F., Krizbai, I.A., Farkas, E., 2018. Large-conductance Ca2+-activated potassium channels are potently involved in the inverse neurovascular response to spreading depolarization. Neurobiol. Dis. 119, 41-52.

Menyhárt, Á., Zölei-Szénási, D., Puskás, T., Makra, P., Tóth, O.M., Szepes, B.É., Tóth, R., Ivánkovits-Kiss, O., Obrenovitch, T.P., Bari, F., Farkas, E., 2017. Spreading depolarization remarkably exacerbates ischemia-induced tissue acidosis in the young and aged rat brain. Sci. Rep. 7 (1), 1154.

Mutch, W.A., Hansen, A.J., 1984. Extracellular pH changes during spreading depression and cerebral ischemia: mechanisms of brain $\mathrm{pH}$ regulation. J. Cereb. Blood Flow Metab. 4 (1), 17-27.

Nedergaard, M., 1996. Spreading depression as a contributor to ischemic brain damage. Adv. Neurol. 71, 75-83 discussion 83-84.

Neri, D., Supuran, C.T., 2011. Interfering with pH regulation in tumours as a therapeutic strategy. Nat. Rev. Drug Discov. 10 (10), 767-777.

Patra, J.K., Das, G., Fraceto, L.F., Campos, E.V.R., Rodriguez-Torres, M.D.P., AcostaTorres, L.S., Diaz-Torres, L.A., Grillo, R., Swamy, M.K., Sharma, S., Habtemariam, S., Shin, H.S., 2018. Nano based drug delivery systems: recent developments and future prospects. J. Nanobiotechnol. 16 (1), 71.

Pickard, J.D., Murray, G.D., Illingworth, R., Shaw, M.D., Teasdale, G.M., Foy, P.M. Humphrey, P.R., Lang, D.A., Nelson, R., Richards, P., et al., 1989. Effect of oral nimodipine on cerebral infarction and outcome after subarachnoid haemorrhage: British aneurysm nimodipine trial. BMJ 298 (6674), 636-642.

Pinard, E., Nallet, H., MacKenzie, E.T., Seylaz, J., Roussel, S., 2002. Penumbral microcirculatory changes associated with peri-infarct depolarizations in the rat. Stroke 33, 606-612.

Reinhart, K.M., Shuttleworth, C.W., 2018. Ketamine reduces deleterious consequences of spreading depolarizations. Exp. Neurol. 305, 121-128.

Richter, F., Ebersberger, A., Schaible, H.G., 2002. Blockade of voltage-gated calcium channels in rat inhibits repetitive cortical spreading depression. Neurosci. Lett. 334 (2), 123-126.

Sadeghian, H., Lacoste, B., Qin, T., Toussay, X., Rosa, R., Oka, F., Chung, D.Y., Takizawa, T., Gu, C., Ayata, C., 2018. Spreading depolarizations trigger caveolin-1-dependent endothelial transcytosis. Ann. Neurol. 84 (3), 409-423.

Sánchez-Porras, R., Santos, E., Schöll, M., Stock, C., Zheng, Z., Schiebel, P., Orakcioglu, B., Unterberg, A.W., Sakowitz, O.W., 2014. The effect of ketamine on optical and electrical characteristics of spreading depolarizations in gyrencephalic swine cortex. Neuropharmacology 84, 52-61.

Sandow, N., Diesing, D., Sarrafzadeh, A., Vajkoczy, P., Wolf, S., 2016. Nimodipine dose reductions in the treatment of patients with aneurysmal subarachnoid hemorrhage. Neurocritical Care 25 (1), 29-39.

Scheller, D., Kolb, J., Tegtmeier, F., 1992. Lactate and pH change in close correlation in the extracellular space of the rat brain during cortical spreading depression. Neurosci. Lett. 135 (1), 83-86.

Scriabine, A., Schuurman, T., Traber, J., 1989. Pharmacological basis for the use of nimodipine in central nervous system disorders. FASEB J. 3 (7), 1799-1806.

Shen, Y., Tang, H., Radosz, M., Van Kirk, E., Murdoch, W.J., 2008. pH-responsive nanoparticles for cancer drug delivery. Methods Mol. Biol. 437, 183-216. https://doi. org/10.1007/978-1-59745-210-6_10.

Shibata, M., Suzuki, N., 2017. Exploring the role of microglia in cortical spreading depression in neurological disease. J. Cereb. Blood Flow Metab. 37 (4), 1182-1191.

Szabó, Í., Tóth, O.M., Török, Z., Varga, D.P., Menyhárt, Á., Frank, R., Hantosi, D., Hunya, Á., Bari, F., Horváth, I., Vigh, L., Farkas, E., 2019. The impact of dihydropyridine derivatives on the cerebral blood flow response to somatosensory stimulation and spreading depolarization. Br. J. Pharmacol. 176 (9), 1222-1234.

van Gijn, J., Kerr, R.S., Rinkel, G.J., 2007. Subarachnoid haemorrhage. Lancet 369 (9558), 306-318.

Varga, V., Németh, J., Oláh, O., Tóth-Szúki, V., Kovács, V., Remzső, G., Domoki, F., 2018. Molecular hydrogen alleviates asphyxia-induced neuronal cyclooxygenase-2 expression in newborn pigs. Acta Pharmacol. Sin. 39 (8), 1273-1283.

Voipio, J., Kaila, K., 1993. Interstitial PCO2 and pH in rat hippocampal slices measured by means of a novel fast $\mathrm{CO} 2 / \mathrm{H}(+)$-sensitive microelectrode based on a PVC-gelled membrane. Pflüg. Arch. 423 (3-4), 193-201.

Woitzik, J., Hecht, N., Pinczolits, A., Sandow, N., Major, S., Winkler, M.K., WeberCarstens, S., Dohmen, C., Graf, R., Strong, A.J., Dreier, J.P., Vajkoczy, P., COSBID study group, 2013. Propagation of cortical spreading depolarization in the human cortex after malignant stroke. Neurology 80 (12), 1095-1102.

Yemişci, M., Gürsoy-Özdemir, Y., Caban, S., Bodur, E., Capan, Y., Dalkara, T., 2012. Transport of a caspase inhibitor across the blood-brain barrier by chitosan nanoparticles. Methods Enzymol. 508, 253-269. 